\title{
A modelagem computacional como ferramenta tecnológica no Ensino de Física
}

\author{
Nascimento, J. O. do ${ }^{1 *}$; Neide, I. G. ${ }^{2}$; Gonzatti, S. E. M. ${ }^{2}$; Moret, M. $A^{1,3}$ \\ 1 Departamento de Modelagem Computacional, Faculdade de Tecnologia SENAI CIMATEC, Salvador, BA, Brasil. \\ 2 Centro de Ciências Exatas e Tecnológicas - CETEC, Centro Universitário UNIVATES, Lajeado, RS, Brasil. \\ 3 Universidade do Estado da Bahia, Salvador, BA, Brasil.
}

*e-mail: jeffersonascimento@gmail.com

\begin{abstract}
Resumo
Os fenômenos astronômicos apresentam como conhecimentos prévios específicos, uma grande quantidade de conteúdos físicos que necessitam ter sido aprendidos de forma significativa, para que esses fenômenos possam ser abordados. Destaca-se, devido às concepções alternativas verificadas pelos discentes nos diversos níveis de ensino, o fenômeno das estações do ano. Diante desta realidade, o presente artigo tem como objetivo apresentar os resultados da aplicação de uma metodologia de ensino para as estações do ano, por meio da modelagem computacional, utilizando o software Modellus. Um estudo de caso foi realizado, em uma pesquisa qualitativa, com o desenvolvimento de uma intervenção pedagógica. Os alunos participantes pertencem a uma turma do curso técnico em informática, na forma da Educação Profissional Técnica Integrada ao Ensino Médio, na modalidade de Educação de Jovens e Adultos (PROEJA). Com o auxílio da modelagem computacional, percebemos indícios de aprendizagem significativa na temática das estações do ano
\end{abstract}

Palavras-chave: Modelagem Computacional, Software Modellus, Estações do ano.

\begin{abstract}
The astronomical phenomena are teaching often in physics without to study its specific previous knowledge that should be consolidated in the student's cognitive structure, so that it can be learned. The highlight, due to verified alternatives for students at various levels of education, is the phenomenon of the seasons of the year. We show in this paper some results regarding the implementation of a methodology for the seasons, through technological tools, grounded in meaningful learning of David Ausubel. The emphasis in the discussion presented here that on the use of computational modeling as an auxiliary tool in the teaching of the phenomenon of the seasons. A case study has done in a qualitative research, with the development of a pedagogical intervention with students from PROEJA (National program of integration between professional education with basic education in the form of youth and adult education). Throughout the intervention performed, we see evidence of meaningful learning in the seasons and its previous knowledge, through of developed activities in computational modeling.
\end{abstract}

Keywords: Computer Modeling, Software Modellus, Season of the years.

\section{Introdução}

Em física, as estações do ano correspondem a um fenômeno astronômico que, embora seja do cotidiano das pessoas, sua compreensão exige a integração de diferentes conceitos, entre eles, situar a Terra como corpo cósmico e desenvolver um modelo tridimensional para o sistema Sol-Terra [1-3]. Conforme os autores anteriores, a causa e a caracterização do fenômeno das estações do ano são tópicos que na educação básica apresentam dificuldades no processo de ensino e aprendizagem. Nascimento, Neide e Borragini [4] verificaram as mesmas concepções alternativas percebidas no ensino médio regular, em relação às estações do ano, em turmas de licenciatura biologia e matemática: o desconhecimento da causa do fenômeno e a caracterização equivocada para o território brasileiro.

Desde os anos iniciais do ensino fundamental, o fenômeno das estações do ano frequentemente é ensinado pela utilização de modelos equivocados, como o da distância [3]. Este modelo propicia outro equívoco: a forma da trajetória exageradamente elíptica da Terra ao redor do Sol [2,3]. Nascimento [3] argumenta que valores com excentricidades de 0,568 são encontrados em livros didáticos, nos diversos 
níveis de ensino. A excentricidade para a trajetória da órbita da Terra ao redor do Sol é de aproximadamente, 0,016 (praticamente circular), ou seja, aproximadamente 36 vezes menor do que é representado nos livros didáticos [3].

Diante do exposto, este artigo tem por objetivo apresentar alguns resultados da pesquisa de dissertação de mestrado do primeiro autor, no que se refere a verificar indícios de aprendizagem significativa, por meio de uma metodologia de ensino para as estações do ano, envolvendo o Software Modellus. Os participantes da pesquisa, corresponderam a trinta alunos (14 homens e 16 mulheres de uma turma do curso Técnico em Informática de PROEJA (Ensino Médio Integrado à Educação Profissional, para alunos a partir de 18 anos).

\section{Aprendizagem significativa e o modelo computacional das estações do ano}

Para que o aprendizado de um determinado material instrucional seja significativo, ele deve ser ancorado em conhecimentos prévios específicos pertencentes à estrutura cognitiva do aprendiz [5]. Assim, ao propormos uma metodologia de ensino para 0 fenômeno astronômico das estações do ano, observamos as palavras de Ausubel (2003) em relação a variável mais importante neste processo de ensino e aprendizagem: verificar o conhecimento prévio presente na estrutura cognitiva do aprendiz e ensiná-lo de acordo. Partindo desta premissa, verificamos que de acordo com Nussbaum [1], Gonzatti [2] e Nascimento [3], dentre outros, o conhecimento prévio específico necessário para o aprendizado das estações do ano, que corresponde a temática de Terra como corpo cósmico.

Para esses autores essa abordagem significa estudar a Terra por meio de sua forma, seu campo gravitacional, seus movimentos e os fenômenos astronômicos decorrentes desses movimentos e da configuração do sistema Terra-Sol-Lua, como por exemplo, dias, noites, estações do ano, fases e eclipses lunares, ou seja, a sua interação com outros astros cósmicos [2,3]. Assim, em termos de organização de conteúdos, Nascimento [3] indica os assuntos e nuances relacionados à Terra, para 0 aprendizado significativo do fenômeno astronômico das estações do ano, conforme exposto na Figura 1:

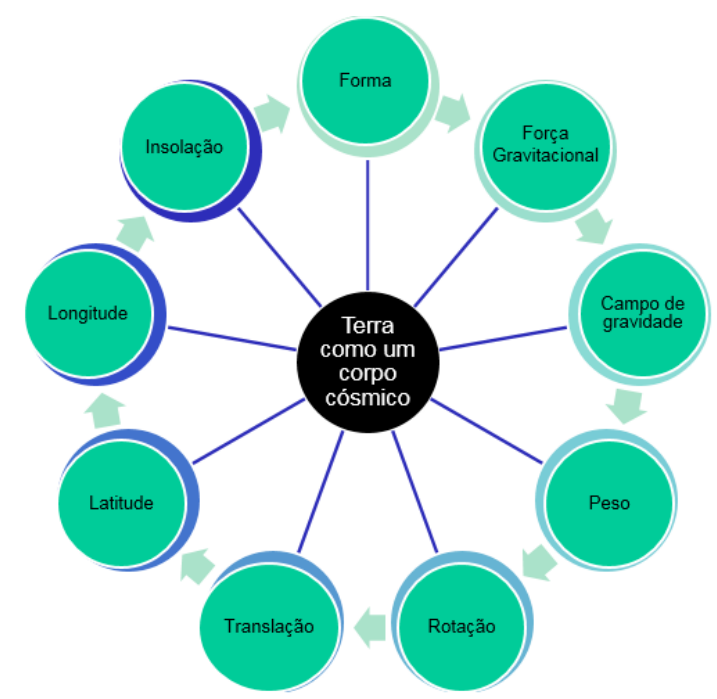

Figura 1 - Conteúdos relacionados à temática de Terra como um corpo cósmico para o Ensino das Estações do Ano. Fonte: Nascimento [3].

Tendo como ponto de partida o conhecimento prévio específico, conforme figura anterior, a proposta metodológica apresentada neste artigo, utilizou a modelagem computacional (com o software Modellus), para o ensino das estações do ano. Alicerçamo-nos em diversos resultados de pesquisas educacionais, que indicam que os processos de ensino e aprendizagem vêm apresentando excelentes indicadores quando os alunos são submetidos a uma forma dinâmica de criação [3]. A modelagem computacional é utilizada neste contexto, por meio de equações matemáticas, sendo possível realizar a representação e descrição de um determinado fenômeno físico para ser estudado [6].

A compreensão de modelagem computacional abordada neste artigo, está de acordo com Araujo [7]: os discentes podem, mesmo que em caráter exploratório, alterar a estrutura básica das equações matemáticas que o constituem o modelo, mesmo não havendo essa necessidade. O software utilizado foi 0 Modellus, devido ao fato de não haver necessidade de aprender uma determinada linguagem de programação pelos alunos, para desenvolver 0 modelo a ser estudado. Um outro motivo corresponde ao fato de se poder criar, ver e interagir com representações analíticas, analógicas e gráficas de objetos matemáticos, para o estudo de um determinado fenômeno. Por fim, é um software livre, cuja distribuição é gratuita (Download disponível em: http://www.modellus.fct.unl.pt/).

\section{Procedimentos metodológicos Análise de pesquisa}

A presente pesquisa objetivou verificar indícios de aprendizagem significativa da temática do fenômeno astronômico das estações do ano, por alunos de uma 
turma do PROEJA. Para isto, entendemos ser necessário a realização de um estudo de caso, por meio de uma intervenção pedagógica, em um contexto real de sala de aula e desta forma, utilizamos as abordagens da pesquisa qualitativa. Conforme Erickson [8] esta escolha de pesquisa tem por interesse indicar 0 significado humano em um contexto social e sua elucidação e exposição pelo pesquisador. Para o autor, o pesquisador deve ter uma forte inserção junto ao espaço social pesquisado e, de forma cautelosa, registrar o que ocorre durante a pesquisa, por meio de fontes diversificadas (anotações, entrevistas, diários de campo, por exemplo).

Destacamos que neste artigo são abordados os resultados do $10^{\circ}$ encontro (última aula antes do pósteste) de uma intervenção pedagógica em que utilizamos a modelagem computacional, por meio do Software Modellus, para a exploração do fenômeno astronômicos das estações do ano. As inferências apresentadas aqui, constituem parte de uma pesquisa maior estruturada da seguinte maneira: realização de um pré-teste semiestruturado (questões abertas e fechadas) para verificar os conhecimentos prévios dos alunos e orientar todo 0 desenvolvimento da intervenção pedagógica (não abordado neste artigo). $\mathrm{Na}$ sequência, do $2^{\circ}$ ao $5^{\circ}$ encontro da intervenção pedagógica (cada um com 4 horas-aula), foram realizadas aulas introdutórias como organizadores prévios ${ }^{1}$. Os conteúdos destas aulas foram norteados com base na Figura 1. Após esses momentos, as aulas com ferramentas tecnológicas $\left(6^{\circ}\right.$ ao $10^{\circ}$ encontro 4horas-aula cada) ocorreram, com a utilização de Objetos de Aprendizagem (também não abordado neste artigo) e do Software Modellus.

Nas Figuras 2-5, o modelo computacional dinâmico desenvolvido para o ensino das estações do ano relacionando aos conteúdos na Figura 1. São apresentadas às características dos solstícios e equinócios durante as realizações dos fenômenos da rotação e translação, dentre outras. O cálculo da excentricidade também é realizado pelo modelo, de forma aproximada. $\mathrm{O}$ modelo matemático que originou o computacional permite a inserção pelo aprendiz, das informações do sistema Sol-Terra. Assim, foram utilizados os valores reais deste sistema, com a observação que: o tamanho dos astros está fora de proporção, mas também podem ser alterados na modelagem computacional.

\footnotetext{
${ }^{1}$ Conforme Moreira [9] os organizadores prévios são formas de apresentação de um determinado conteúdo (material), "[...] em um nível mais alto de abstração, generalidade e inclusividade do que esse material".
}

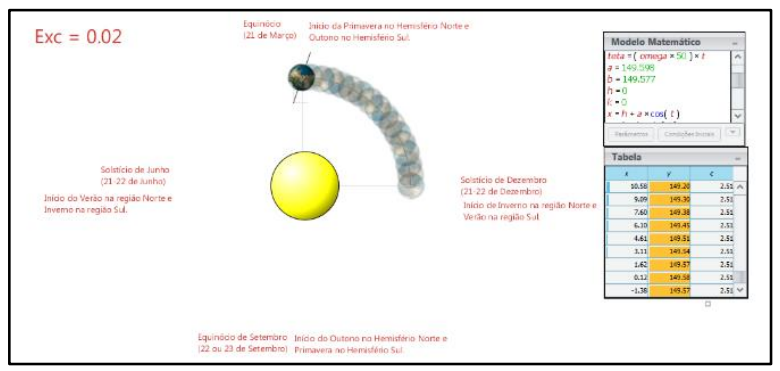

Figura 2 - Modelagem dos Solstícios de dezembro e equinócios de março. Fonte: Nascimento (2015).

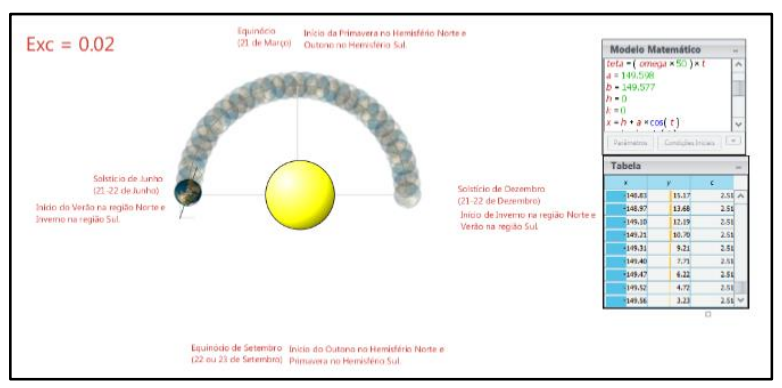

Figura 3 - Modelagem dos equinócios de março e Solstícios junho. Fonte: Nascimento (2015).

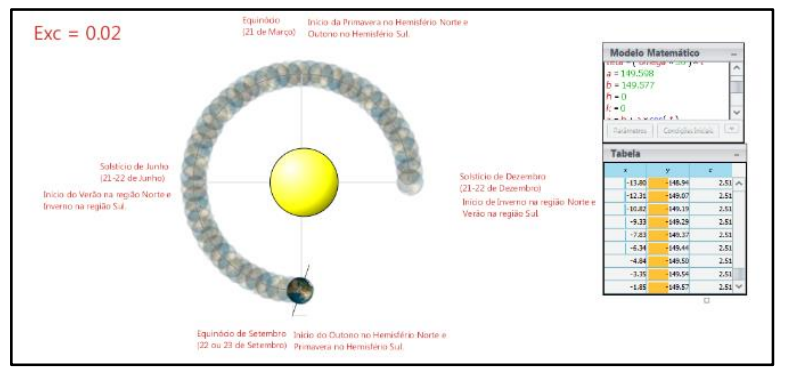

Figura 4 - Modelagem dos Solstícios de junho e Equinócios de Setembro. Fonte: Nascimento (2015).

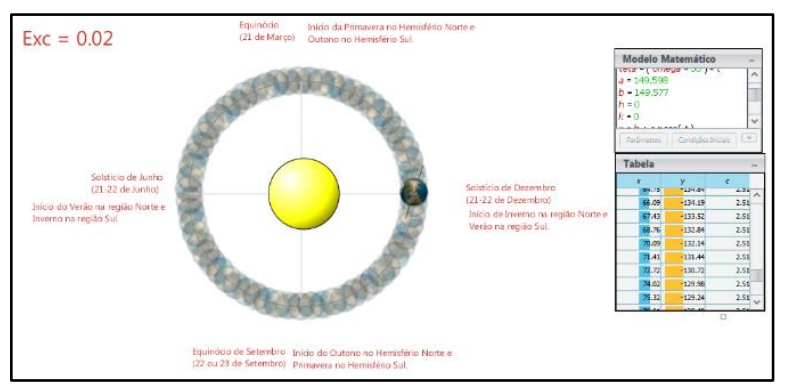

Figura 5 - Modelagem dos Equinócios de Setembro e Solstícios de Dezembro. Uma visão geral da modelagem. Fonte: Nascimento (2015).

Para manter a integridade na identificação dos participantes da pesquisa, iremos nos referir a eles como A1 (aluno 1), A2 (aluno 2), A3 (aluno 3) e assim sucessivamente. $O$ estudo de estações do ano utilizando a modelagem computacional por meio do Software Modellus, foi norteado por um roteiro de atividades utilizado em conjunto com a modelagem. Tanto para a elaboração deste roteiro com questões, quanto a atividade de modelagem computacional utilizada pelo discentes, observamos os nortes da psicologia cognitiva de Ausubel [5]. Assim, ambos seguiram concomitantemente os princípios da reconciliação integradora e diferenciação progressiva. 
Para Moreira [9] significa que para o discente, ao interagir com todos os supracitados materiais de ensino, devem apresentar uma estrutura lógica "[...] isto é, seja relacionável de maneira não-arbitrária e nãoliteral a uma estrutura cognitiva apropriada e relevante". Materiais elaborados com esta premissa são denominados de potencialmente significativos e podem ajudar a satisfazer uma outra condição para o aprendizado significativo: "o aprendiz deve apresentar uma predisposição para aprender” (ibidem).

A primeira questão, com o intuito explorar o modelo computacional, solicitava que os discentes utilizassem diferentes valores para a excentricidade e assim, pudessem visualizar a correspondência com a forma da trajetória de revolução da Terra ao redor do Sol. Esta primeira abordagem teve um caráter exploratório. A segunda questão solicitava que os alunos explicassem o motivo da trajetória visualizada na modelagem, ser semelhante a uma circunferência. Apresentamos a seguir a resposta do aluno A3 e A15, respectivamente: "Os valores dos semieixos são muito próximos e sua excentricidade é muito baixa", "A excentricidade é muito baixa". As respostas do aluno A3 e A15 corretas cientificamente, correspondendo ao padrão verificado nas respostas de dezesseis alunos, em que conseguiram argumentar e associar o formato da trajetória modelada à excentricidade, e esta com os valores dos semieixos.

A terceira questão solicitava que os alunos citassem as estações que iniciam nos solstícios e explicassem o significado dessas datas. Dezessete alunos apresentaram argumentações corretas cientificamente. Como exemplo que ilustra o perfil de respostas verificado, apresentamos o argumento do aluno A15: "Solstício é uma data do ano que a cada semestre muda a estação, verão e inverno". Conforme Gonzatti [2] as estações inverno e verão têm seus inícios (22/06 e 22/12, aproximadamente) marcados pelos solstícios de inverno e verão, respectivamente, considerando-se o Hemisfério Sul. Enquanto em um Hemisfério da Terra ocorre o inverno para o outro ocorrerá o verão.

A quarta questão solicitava que os alunos respondessem quais estações iniciavam nos equinócios e o significado destas datas. Quatorze deles responderam de forma correta, como é possível perceber nos excertos dos alunos A2, A4 e A12, respectivamente: "É uma data que marca o início da primavera e outono"; "inicia primavera e outono, é uma data que acontece em março ou setembro, acontece a cada 6 meses"; e "Equinócio é o início das estações primavera e outono". As estações outono e primavera têm seus inícios nas datas de equinócios (21/03 e 24/09, aproximadamente, para um observador localizado no hemisfério Sul terrestre) e, pelo fato de nesses dias os raios solares incidirem perpendicularmente em relação ao equador da Terra, ambos os Hemisférios do planeta são iluminados de forma equivalente [2,3]. As respostas dos alunos transcritas acima, possivelmente indicam a percepção que obtiveram no período que separa um solstício do outro e que o termo caracteriza o início de duas estações em Hemisférios diferentes da Terra.

$\mathrm{Na}$ quinta questão se exigia que os alunos explicassem, em função da duração do dia e da noite, a diferença entre solstícios e equinócios. Apenas doze alunos apresentaram respostas corretas, dentre elas, apresentamos as dos discentes A8, A16 e A30, respectivamente: "solstícios têm mais que o equinócio e o equinócio é igual dia e noite", "Solstícios são diferentes e equinócios iguais" e "equinócio, o tempo de dia igual a noite, solstícios dias maiores que as noites".

As argumentações dos alunos supracitados, refletem o padrão verificado nas demais respostas corretas e, descrevem que nos solstícios ocorrem diferentes durações do período de claridade e escuridão nos hemisférios da Terra e uma igualdade destes períodos nos equinócios. Contudo, conforme Nascimento [3], possivelmente esses conceitos apresentaram-se de forma mecânica, em decorrência da enorme dificuldade demonstrada nas argumentações realizadas pelos alunos. No caso da resposta do aluno $\mathbf{A} 30$, pode-se perceber que ele sabe que nos solstícios há desigualdade na duração do dia, embora nem sempre os dias sejam maiores que as noites. Isso é correto para o solstício de verão, mas não para o solstício de inverno.

A sexta questão solicitava que os alunos citassem a causa para a ocorrência das estações do ano. Vinte e três alunos argumentaram de forma correta cientificamente e dois não responderam. Apresentamos as respostas dos alunos A2 e A24, a título de exemplo: A2: "O fator responsável pelas estações do ano é a inclinação do eixo da terra em 23,50". A24: "O eixo imaginário da terra, 23,5品. Nessas respostas, é possível perceber que os alunos assimilaram que a ocorrência das estações do ano é explicada pela inclinação do eixo terrestre em relação ao seu plano da translação.

Conforme já abordado, um dos erros mais comuns na temática das estações do ano é o de se admitir como causa do fenômeno uma maior ou menor proximidade entre a Terra e o Sol (o modelo das distâncias), não havendo citação por parte dos alunos deste modelo na presente questão. A sétima questão requeria que os alunos explicassem as características das estações verão e inverno nos diferentes hemisférios da Terra. Dezenove alunos responderam de forma coerente, considerando a influência das latitudes e das diferentes zonas climáticas existentes. Apresentamos a resposta do aluno A2 como exemplo das recorrentes argumentações fornecidas pelos alunos nesta questão: 
"Em zonas temperadas temos estações do ano definidas, verão muito sol, inverno é neve, primavera são só de flores e outono os frutos. Em zonas não temperadas (intertropical) as estações dependem de cada região no Brasil, por exemplo, não temos estações definidas, temos sol, chuva, flores e frutas o tempo todo, ou seja, o ano inteiro".

$\mathrm{Na}$ oitava questão foi proposto que os alunos explicassem as características das estações primavera e outono, respectivamente. Quatorze discentes responderam segundo uma perspectiva teórica semelhante à utilizada na questão anterior (sétima). A título de exemplo, apresentamos as respostas dos alunos A11, A19 e A26, descritas respectivamente na sequência: "Primavera e outono nas regiões temperadas são bem definidas e fora dessa região existem particularidades do local", "região temperada tem flores, frutas, queda de folha de árvores, onde não é região temperada não tem divisão, depende da região" e "Em zonas como a temperada outono tem fruta e primavera tem flores, nas outras não tem definição".

As argumentações dos discentes indicam que possivelmente estabeleceram a diferença na caracterização das estações em função das regiões analisadas, contrapondo a problemática destacada em Nascimento [3]. Essa problemática diz respeito ao modelo didático de estações que é ensinado ao aluno: com características europeias ou de acordo com outras regiões do Hemisfério Norte, que não refletem a realidade brasileira. Esta situação é provocada, em boa medida, pelo fato que em muitos materiais de ensino utilizados no Brasil, o fenômeno das estações, no território nacional, é caracterizado de forma equivocada, desconsiderando os diferentes microclimas presentes nesse território (ibidem). De acordo com Ausubel [5], as respostas dos alunos podem indicar a ocorrência da diferenciação progressiva, com uma possível evolução conceitual na forma de caracterização das estações.

A nona questão explorou informações referentes ao fato que em janeiro há uma insolação solar maior do que em junho, o que torna as estações do ano mais rigorosas onde se encontra o Brasil, no Hemisfério Sul. Requeria-se dos alunos que explicassem esta afirmativa. Esta questão teve o menor número de acertos, uma vez que apenas dez alunos deram respostas corretas cientificamente e cinco não responderam. Apresento as respostas dos alunos A6, A14 e A22, transcritas de forma respectiva na sequência: "não, por conta do efeito ambiental que contrabalanceia esses 6\%", "Não, no "hemisfério" sul as estações sofrem interferência dos efeitos ambientais" e "não, o meio ambiente compensará os 6\%". Conforme Kepler e Saraiva apud Nascimento (2015) mesmo em janeiro, com a insolação solar sendo
$6 \%$ maior do que em junho, as estações do ano não se tornam mais rigorosas no Hemisfério onde se encontra - Brasil, por conta do contrabalanceamento proporcionado pela maior quantidade de água nesse hemisfério. As respostas corretas dos alunos, transcritas acima, fundamentaram-se em função de fatores ambientais.

A décima questão solicitava que os alunos explicassem o motivo de ocorrerem ou não as quatro estações do ano em Belém/PA. Dos trinta participantes da pesquisa, vinte e três alunos responderam de forma correta a questão, como por exemplo, o aluno A24: "Não. Porque não estamos em zona temperada, estamos numa zona indefinida, na verdade temos vários microclimas". Conforme discutido em Gonzatti [2] e Nascimento (2015) as quatro estações do ano com características bem definidas, que as distinguem entre si, são típicas de algumas regiões pertencentes ao Hemisfério Norte, apresentando mudanças na paisagem (clima temperado), nos seres vivos, nos frutos e no florescimento de plantas.

Para o Brasil, o mais adequado é a abordagem do fenômeno por meio da associação às regiões do território nacional, haja vista não ocorrerem os contrastes típicos do clima temperado [3]. Estas características foram apresentadas pelos respondentes da presente questão, indicando um possível indício de aprendizagem na temática em questão.

\section{Considerações finais}

Nossa intenção neste artigo, foi de apresentar alguns resultados obtidos com alunos de uma turma do PROEJA técnico em informática, em busca de indícios de aprendizagem significativa na temática de estações do ano. Por meio da proposta de ensino realizada apresentamos também, na presente discussão, um modelo computacional do referido fenômeno, utilizando o software Modellus. Contudo, percebemos em alguns momentos 0 aprendizado mecânico durante a intervenção, como o que ocorreu com o estudo do solstícios e equinócios. As dificuldades nas explicações e aplicações destes tópicos em diferentes formas e níveis de resolução de problemas apresentados, alicerçam essa percepção. Entretanto, diante das respostas e argumentações dos alunos durante as demais questões, podemos inferir que indícios de aprendizagem significativa foram verificados, com ao auxílio das atividades de modelagem. 


\section{Agradecimentos}

O primeiro autor agradece à FAPESB, devido ao apoio financeiro parcial por meio de sua bolsa de doutorado (BOL170/2015). O último autor agradece ao CNPq pelo suporte financeiro parcial oriundo de sua bolsa de Produtividade em Pesquisa (No. 304454/2014-1).

\section{Referências}

[1] NUSSBAUM, J. Children's Conceptions of the Earth as a Cosmic Body: a cross age study. Science Education, New York, v. 63, n. 1. p. 83-93, Jan. 1979.

[2] GONZATTI, Sônia Elisa Marchi. Um Curso Introdutório à Astronomia para a Formação Inicial de Professores de Ensino Fundamental, em nível médio. 2008. 260 f. Dissertação (Mestrado Profissional em Ensino de Física) - Instituto de Física, Universidade Federal do Rio Grande do Sul, Porto Alegre, 2008.

[3] NASCIMENTO, Jefferson Oliveira do. O Ensino de Física por meio de ferramentas tecnológicas: um estudo de caso com o PROEJA. 2015. $231 \mathrm{f}$. Dissertação (Mestrado em Ensino de Ciências Exatas) - Centro Universitário UNIVATES, Lajeado, 25 set. 2015.

[4] NASCIMENTO, J. O. do; NEIDE, I. G., BORRAGINI, L. F. Modelagem Computacional com o Software Modellus: Estudando as Estaçõe do Ano. In: XV EPEF Encontro de Pesquisa em Ensino de Física, 2014, São
Sebastião, Maresias, SP. Anais do XV EPEF, 2014. v. 1. p. 1-8.

[5] AUSUBEL, David Paul. Aquisição e retenção de conhecimento: uma perspectiva cognitiva. Lisboa: Plátano Edições Técnicas, 2003.

[6] TEODORO, Vítor Duarte; NEVES, Rui Gomes. Mathematical modelling in science and mathematics education. Computer Physics Communications, v. 182, n. 1, p. 8-10, 2011.

[7] ARAUJO, Ives Solano. Simulação e modelagem computacionais como recursos auxiliares no ensino de física geral. 2005. 238 f. Tese (Doutorado em Ensino de Física) - Instituto de Física. Universidade Federal do Rio Grande do Sul, Porto Alegre, 2005.

[8] ERICKSON, F. Qualitative methods in research on teaching. In Wittrock, M.C. (Ed.). Handbook of research on teaching. New York: Macmillan Publishing Co. p. 119-161, 1986.

[9] MOREIRA, Marco Antônio. Aprendizagem significativa, organizadores prévios, mapas conceituais, diagramas $\mathrm{V}$ e unidades de ensino potencialmente significativas. I Encontro Regional de Aprendizagem Significativa I ERAS NORTE. UEPA, Belém, 2013. Disponível

em: <http://paginas.uepa.br/erasnorte2013/images/sampled ata/figuras/aprend_\%20signif_\%20org_prev_mapas_co nc_diagr_v_e_ueps.pdf>. Acesso em: 23 abr. de 2014 